\title{
Review of Environmental Assessment Case Studies Blending Elements of Risk Assessment and Life Cycle Assessment
}

\author{
Robin Harder, ${ }^{* \dagger}$ Hanna Holmquist, ${ }^{\dagger}$ Sverker Molander, ${ }^{\dagger}$ Magdalena Svanström, ${ }^{\dagger}$ and Gregory M. Peters ${ }^{\dagger}$ \\ ${ }^{\dagger}$ Chemical Environmental Science, Department of Chemistry and Chemical Engineering, Chalmers University of Technology, SE-412 \\ 96 Gothenburg, Sweden \\ ${ }^{\ddagger}$ Environmental Systems Analysis, Department of Energy and Environment, Chalmers University of Technology, SE-412 96 \\ Gothenburg, Sweden
}

\section{Supporting Information}

ABSTRACT: Risk assessment (RA) and life cycle assessment (LCA) are two analytical tools used to support decision making in environmental management. This study reviewed 30 environmental assessment case studies that claimed an integration, combination, hybridization, or complementary use of RA and LCA. The focus of the analysis was on how the respective case studies evaluated emissions of chemical pollutants and pathogens. The analysis revealed three clusters of similar case studies. Yet, there seemed to be little consensus as to what should be referred to as RA and LCA, and when to speak of combination, integration, hybridization, or complementary use of RA and LCA. This paper provides clear recommendations toward a more stringent and consistent use of terminology. Blending elements of RA and LCA offers multifaceted opportunities to adapt a given environmental assessment

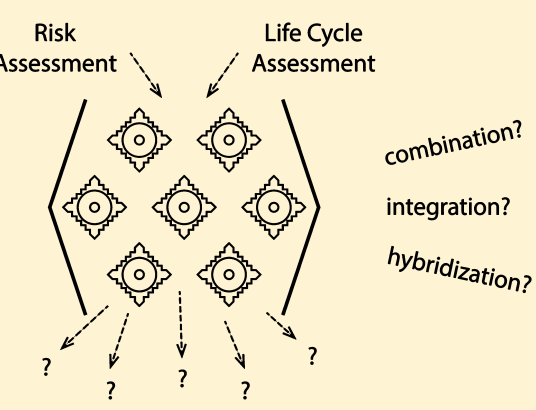
case study to a specific decision making context, but also requires awareness of several implications and potential pitfalls, of which six are discussed in this paper. To facilitate a better understanding and more transparent communication of the nature of a given case study, this paper proposes a "design space" (i.e., identification framework) for environmental assessment case studies blending elements of RA and LCA. Thinking in terms of a common design space, we postulate, can increase clarity and transparency when communicating the design and results of a given assessment together with its potential strengths and weaknesses.

\section{INTRODUCTION}

Risk assessment (RA) and life cycle assessment (LCA) are two analytical tools used to support decision making in environmental management. RA and LCA were initially developed and used by largely separate groups of specialists. ${ }^{1}$

RA is a very broad analytical tool that is applicable in many different contexts. The present study focuses on RA in the context of environmental management and does not address $\mathrm{RA}$ in the context of safety and reliability engineering (e.g., risk assessment of power plants based on the analysis of fault trees and event trees). In the context of environmental management, $\mathrm{RA}$ is often concerned with evaluating the risks posed by stressors, such as chemical pollutants or pathogens, to humans and other receptors. Risk is commonly defined as a combination of the probability and the severity (nature and magnitude) of effects from a proposed action. ${ }^{2,3}$ The quantitative assessment of chemical risks is often labeled as ecological risk assessment, environmental risk assessment, human health risk assessment, or human and environmental risk assessment. The quantitative assessment of pathogen risks is usually labeled as quantitative microbial risk assessment (QMRA)

LCA is an analytical tool for the environmental assessment of products or services and generally covers the entire life cycle, or supply chain, of a product or service. Environmentally relevant resource consumption and emissions throughout this life cycle are quantified with respect to a functional unit, and the related potential impacts on a number of safeguard subjects (e.g., human health, natural environment, and natural resources) are estimated. LCA methodology has developed considerably since its emergence in the late $1970 \mathrm{~s},{ }^{4}$ and several life cycle inventory (LCI) databases and life cycle impact assessment (LCIA) methods are available. LCIA methods cover a continuously expanding number of impact categories and corresponding characterization models for the conversion of emissions from, and resources used in, the life cycle of a product or service into impacts. $^{5}$ This type of LCA may also be referred to as environmental LCA (E-LCA) in order to distinguish it from social LCA (S-LCA) and life cycle costing (LCC).

Both RA and LCA can be used to evaluate the effects of chemical pollutants and pathogens emitted to the environment on humans and other species. In both analytical tools, the assessment requires information about emissions, fate and transport in the environment, exposure of different receptors, and effects on different receptors. Early attempts to include

Received: April 8, 2015

Revised: October 10, 2015

Accepted: October 26, 2015

Published: November 6, 2015 
human toxicity and ecotoxicity of chemical pollutants in LCA were to a large extent inspired by expert knowledge and mathematical relationships established within chemical RA. ${ }^{6-10}$ In a similar way, early efforts to include the effects of pathogens on human health in LCA were largely inspired by QMRA. ${ }^{11}$

The similarities, differences, and potential synergies between RA and LCA have been thoroughly discussed on a theoretical level in a special issue of Risk Analysis in 2002, ${ }^{1,12-14}$ a special section in Human and Ecological Risk Assessment in 2006, ${ }^{15-18}$ and in regular issues of various other journals. ${ }^{19-21}$

RA focuses on comparing the predicted total exposure of certain receptors to certain stressors with corresponding thresholds, or on predicting the likelihood of a certain effect, mostly applying a reasonable worst-case scenario approach. Depending on its purpose, RA covers one or several stressors (i.e., chemical pollutants and pathogens) and one or several receptors (i.e., humans or specified other ecological entities) at one or several sites. RA for a certain activity could encompass several stressors and receptors at one site, but disregard emissions of these stressors and the effects on these receptors elsewhere. This kind of RA could be conducted, for example, in the permitting process for industrial activities under the environmental protection legislation of a given country. RA could also encompass emissions of a substance from different sources and at different locations throughout the life cycle of a substance.

LCA typically compares the environmental performance of different product or service systems, or different life cycle phases of a product or service system, for average conditions (routine operations under steady-state conditions). Traditionally, LCA does not take into account the time-space distribution of stressors, the existence of toxicity thresholds, or varying acceptability of impacts.

Even though the basic ingredients of RA and LCA (i.e., the environmental processes and phenomena that are to be incorporated, the mathematical relationships postulated for each of these phenomena, and the chemical and environmental data needed in these relationships) are largely similar, RA and LCA can supply decision makers with different types of information. ${ }^{17}$ Early examples of the complementarity of the perspectives provided by RA and LCA are prospective environmental assessments in the context of contaminated site remediation ${ }^{22}$ and bleaching of mechanical pulp, ${ }^{23}$ and a retrospective comparison of the environmental profile of laundry detergents at different points in time. ${ }^{24,25}$ In recent years, several other environmental assessment case studies were published that claimed an integration, combination, hybridization, or complementary use of RA and LCA. The goal of the present study was to analyze thoroughly these more recent environmental assessment case studies blending elements of RA and LCA in one way or another.

\section{METHODS}

We searched the Scopus database for environmental assessment case studies containing the terms "life cycle assessment" and "risk assessment", "life cycle impact assessment" and "risk assessment", or "life cycle risk assessment" in the title, abstract, or keywords (i.e., ("life cycle assessment" AND "risk assessment") OR ("life cycle impact assessment" AND "risk assessment") OR "life cycle risk assessment"). The abbreviations LCA and LCIA as well as alternative spellings (i.e., "lifecycle" and "lifecycle") were included in the search. The literature search yielded 30 environmental assessment case studies. These case studies were analyzed in an iterative manner. The three overarching questions were as follows: what methodological characteristics distinguish environmental assessment case studies blending elements of RA and LCA; has a unified terminology emerged; and what can be learnt for future environmental case studies blending elements of RA and LCA? A preliminary screening focusing on the methodological characteristics of the reviewed case studies helped to identify clusters of similar studies, as well as a set of characteristics distinguishing the clusters from one another. The methodological differences were then scrutinized in order to reveal similarities and differences related to the choice of cause-effect chain models and associated parameters. The focus of the analysis hereby was on how the respective case studies evaluated emissions of chemical pollutants and pathogens.

\section{RESULTS}

Typology of Case Studies. The environmental assessment case studies investigated in this study displayed a considerable flexibility in terms of how elements of RA and LCA were blended. We identified three clusters of similar case studies (Figure 1).

Site-Dependent Assessment (Cluster 1). Several case studies aimed at a site-dependent estimation of health risks in a given country, such as those resulting from emissions of particulate matter, ${ }^{26-29}$ airborne hexavalent chromium, ${ }^{30}$ or decabromodiphenyl ether. ${ }^{31}$ In these studies, environmentally extended input-output analysis (EEIOA) was the starting point for a spatially differentiated (site-dependent) assessment of human health risks. These studies all claimed to have blended elements of RA and LCA. Yet, it should be noted that a very similar overall model structure also results from efforts toward increased spatial differentiation through site-dependent impact assessment in LCIA, such as the development of spatially differentiated fate, transport, and exposure models for human toxicity and ecotoxicity. ${ }^{32,33}$

Application of Life Cycle Thinking in RA (Cluster 2). A product/service-based life cycle perspective can also be applied in RA. ${ }^{34,35}$ This implies that the purpose of RA does not remain restricted to one central substance or site, but the assessment considers emissions of one or several substances from different sources and at different locations throughout different life cycle stages of a product or service. Shih and $\mathrm{Ma},{ }^{36}$ for instance, investigated human health risks associated with heavy metal release during bottom ash treatment, reuse of bottom ash in pavement, and disposal of bottom ash in a landfill (after reuse in pavement or directly after ash treatment). Milazzo and Spina ${ }^{37}$ investigated human health risks along the production chain of biodiesel. Such life cycle risk assessment (LCRA) has also been applied to risks other than chemical risks. Aissani and colleagues, ${ }^{38}$ for example, investigated the risk of accidents in two energy pathways at different life cycle stages.

Trade-off between Local and Global Effects (Cluster 3). In the field of contaminated site remediation, which traditionally has been more concerned about mitigation of local risks (primary impacts), it has been recognized that a focus on local risk mitigation measures may simply shift the effects elsewhere if life cycle impacts of the risk mitigation measures (secondary impacts) are not considered. ${ }^{39-44}$ Such problem shifting may also occur in the context of water and wastewater treatment, where the removal of chemical pollutants and pathogens through treatment operations may reduce health impacts caused locally at the expense of health impacts caused 

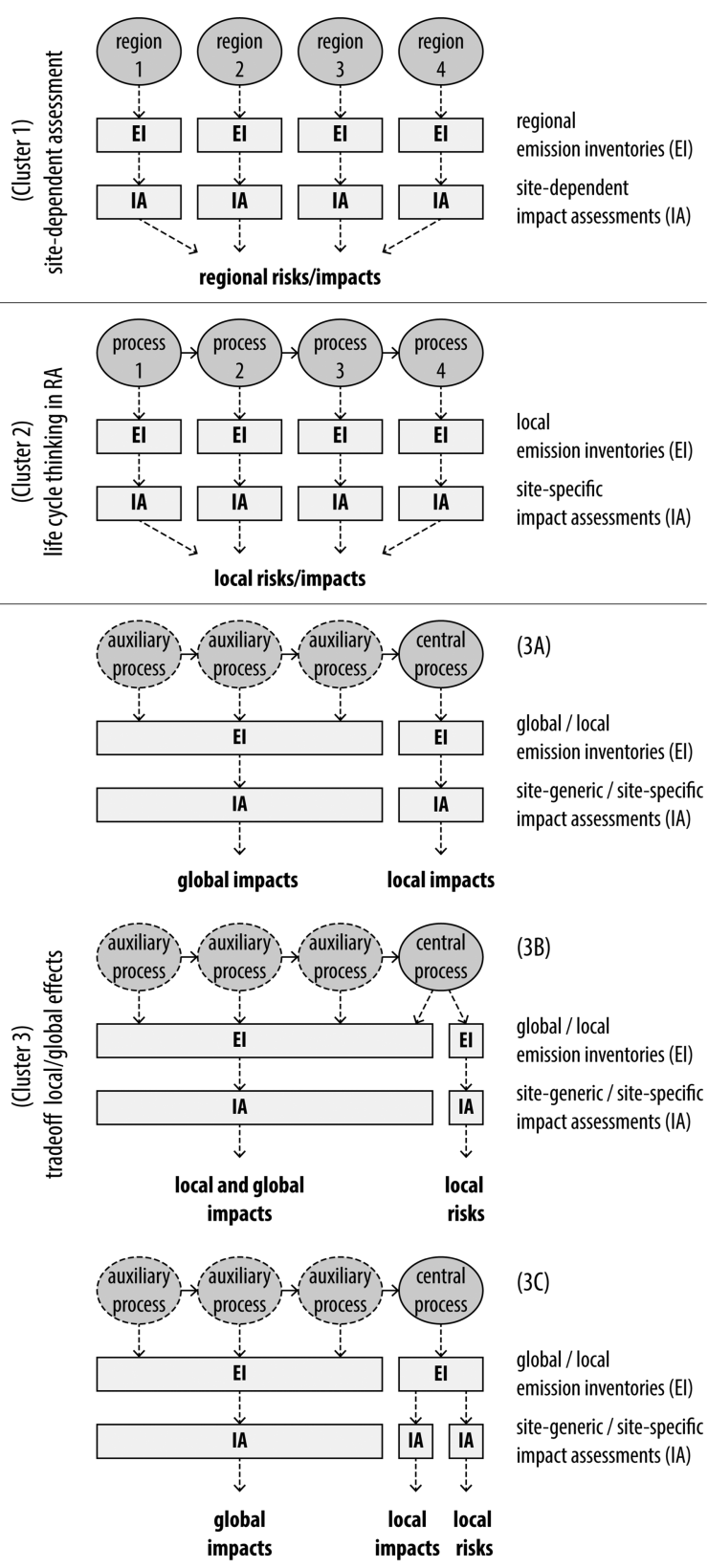

Figure 1. Plurality of model structures. Three clusters of similar case studies were identified. Note that "risk" denotes that the assessment is meant to address the distribution and acceptability of an effect at the level of individuals, whereas "impact" denotes that the assessment is meant to address the overall impact at the level of a population.

elsewhere (possibly by other stressors) as a result of, for instance, energy production required for treatment operations. ${ }^{11,45-47}$

A comparison between local and global impacts could in principle be made entirely within an LCA framework. For example, LCIA methods could be applied to local emissions separately. ${ }^{39,48}$ However, many case studies recognized the need for more site-specific assessments to address local impacts in LCA (cluster 3A). In the field of contaminated site remediation, for example, it was recognized that the estimation of the environmental impacts of contaminant leaching would require site-specific fate and exposure models. ${ }^{42-44}$ The importance of including site-specific fate and exposure models for chemical toxicity was also acknowledged in other contexts, such as metal degreasing, ${ }^{49}$ rotogravure printing, ${ }^{50}$ textile production, $^{51}$ road and earth construction, ${ }^{52}$ water and wastewater treatment, ${ }^{47}$ and land application of sewage sludge. ${ }^{53}$ Similar to the efforts to include site-specific models for chemical risk in LCA, also attempts to include pathogen risk in LCA relied on site-specific fate and exposure models. ${ }^{11,45,46,54}$ The case studies belonging to cluster $3 \mathrm{~A}$ have a model structure where certain cause-effect chains from emission to receptor are investigated separately for a central process using site-specific fate and transport models, and for the auxiliary processes supporting this central process using generic fate and transport models, respectively.

Many case studies also sought to take into account aspects of distribution and acceptability of local risks for specific members of a human population (clusters $3 \mathrm{~B}$ and $3 \mathrm{C}$ ). Contexts where these aspects were taken into account include contaminated site remediation, ${ }^{39-41}$ metal degreasing, ${ }^{49,55,56}$ rotogravure printing, ${ }^{50}$ plastic bottle design, ${ }^{57}$ alumina nanofluid production, ${ }^{58}$ electronic waste recycling, ${ }^{59}$ material recycling in roadway construction, ${ }^{60,61}$ and apple orchard management. ${ }^{62}$ The case studies belonging to clusters $3 \mathrm{~B}$ and $3 \mathrm{C}$ have a model structure where some cause-effect chain models represent overall impacts for a given human population (henceforward referred to as LCA perspective) and other cause-effect chain models represent risks for specific members of a given human population (henceforward referred to as RA perspective). The cause-effect chain models used to estimate local risks (RA perspective) are usually site-specific. The cause-effect chain models used to estimate overall impacts (LCA perspective) can in principle be site-generic (i.e., no spatial differentiation in sources and receiving environments), site-dependent (i.e., some spatial differentiation), or site-specific (i.e., very detailed spatial differentiation) (see also Potting and Hauschild ${ }^{63}$ ). In most case studies, the estimation of overall impacts (LCA perspective) did not distinguish between global and local impacts (cluster 3B). ${ }^{39-41,51,55-62}$ In some other case studies, the estimation of overall impacts (LCA perspective), as in cluster $3 \mathrm{~A}$, featured site-specific fate and exposure models for local impacts (cluster 3C). ${ }^{49,50}$

Most of the case studies belonging to clusters $3 \mathrm{~B}$ and $3 \mathrm{C}$ reported the results obtained for the LCA perspective and the RA perspective separately with intent to broaden decision support. The concept of disability-adjusted life years (DALY) (see Murray ${ }^{64}$ ) has been adopted in both RA and LCA, and enables to express the outcomes of both perspectives in terms of a common indicator. Other studies used multicriteria analysis methods ranging from the use of weighting factors ${ }^{39}$ to more complicated approaches, ${ }^{41,57,60,62,65}$ in order to weight and aggregate the results representing the two different perspectives.

Use of Terminology. The review of the case studies brought about some interesting findings regarding the use of terminology. The terms risk and impact seem to be applied fairly consistently within and across studies, whereas consensus seems to be lacking with regard to the terms combination, integration, hybridization, and complementary use of RA and LCA.

Risk or Impact? For chemical pollutants, effects at the global scale are consistently referred to as global impacts, whereas effects at the local scale are sometimes referred to as local risks and sometimes as local impacts. Nevertheless, there appears to be a consensus to speak of local risks when the site-specific local assessment concerns the exposure of specific individuals 
(RA perspective), and of local impacts when the assessment concerns the aggregate exposure of a population (LCA perspective). Only a few studies deviated. For example, Kikuchi and Hirao ${ }^{49}$ seem to have addressed both perspectives and used both terms interchangeably to refer to both perspectives. This ambiguity, however, was resolved in later studies by the same authors. $^{55,56}$

For pathogens, only effects at the local scale were considered in the studies reviewed. These effects were consistently referred to as pathogen risk. If the above use of terminology were applied also to studies attempting to include the effects of pathogens on human health in LCA, the respective effect should perhaps be referred to as pathogen impact or pathogen impact potential, rather than pathogen risk. The term pathogen risk would then be used to refer to the effect of pathogens on specific individuals (RA perspective) rather than a given population as a whole (LCA perspective). Combination, integration, hybridization, or complementary use of $R A$ and LCA?

Case studies aiming at a site-dependent assessment (cluster 1) essentially combined EEIOA (the use of which is common in LCA) with environmental fate, exposure, and effect assessment models (of the type commonly used in RA). This approach is concisely described only by one study. ${ }^{30}$ The other four studies belonging to cluster 1 are less concise and speak of a combination or integration of EEIOA-LCA with RA, ${ }^{29,31}$ an integration of RA and $\mathrm{LCA},{ }^{26}$ or the incorporation of regional variability into EEIOA-LCA. ${ }^{27,28}$

Case studies applying life cycle thinking to RA (cluster 2) have referred to their efforts as integration of lifecycle thinking into $\mathrm{RA}^{36}$ or integrated use of RA and LCA. ${ }^{37}$

The term hybridization has been used for some time in the context of LCI construction from parallel use of EEIOA and process analysis. ${ }^{66}$ More recently, it was used in studies attempting to include pathogen risk in an LCA framework $^{45,46,54}$ to describe the use of QMRA in an LCA framework (subset of cluster $3 \mathrm{~A}$ ).

In studies accounting for different perspectives (clusters $3 \mathrm{~B}$ and $3 \mathrm{C}$ ), the terms combination and integration appear to have been used fairly interchangeably, although some case studies speak of a complementary use of RA and $\mathrm{LCA}^{51,52}$ or a comprehensive assessment tool, ${ }^{62}$ or make no attempt to label their approach. ${ }^{59}$

Proposition of a Design Space for Case Studies Blending Elements of RA and LCA. In light of the ambiguity regarding what should be referred to as RA and LCA, as well as different interpretations of what integration, combination, hybridization, or complementary use of RA and LCA actually means, we think it would be useful to transcend the RA-LCA dichotomy underlying many previous studies, and instead approach the different case studies in terms of a common design space. The characteristics of the 30 environmental assessment case studies analyzed in this paper are summarized in the Supporting Information using the design space proposed and described here.

The proposed design space is similar to the evaluative framework for the evaluation of conceptual and analytical approaches used in environmental management proposed by Baumann and Cowell, ${ }^{67}$ and the identification key for selecting methods for sustainability assessments proposed by Zijp and colleagues. $^{68}$ Rather than targeting the choice of a certain assessment framework (i.e., RA framework or LCA framework), the design space proposed in this paper presupposes that an environmental assessment framework blending elements of RA and LCA is adequate, and outlines choices to be made within this type of assessment framework when blending elements of RA and LCA. However, the proposed design space does not give detailed instructions on how individual components (i.e., RA perspective or LCA perspective) should be designed, as other sources $^{69}$ are useful in this regard.

The main idea behind the proposed design space is to facilitate a better understanding and more transparent communication of the nature of a given case study by asking a number of specific questions pertaining to different aspects of the design space. These questions include both the characteristics of the study as a whole and the characteristics of the cause-effect chains related to chemical pollutants and pathogens. The design space provided the basis for the characterization of the reviewed case studies in the Supporting Information. The different aspects of the design space are illustrated in Figure 2.

Regarding a given case study as a whole, four questions are useful: what is the orientation of the study (i.e., substanceoriented, product/service-oriented, process-oriented), which perspectives are covered (i.e., RA perspective only, LCA perspective only, or both perspectives), which impact categories are covered, and which cause-effect chains are covered?

Regarding the details of the cause-effect chains related to chemical and pathogen risks, the following questions are useful: what type of risk or impact does the given cause-effect chain represent and what is the perspective (i.e., RA perspective or LCA perspective) addressed by the given cause-effect chain model, what is the assessment end point of the study (i.e., is the category indicator based on emissions, environmental concentrations, or effects on receptors), what types of uncertainty are considered and how are they handled, how is data assigned to the emission inventory (i.e., via EEIOA or process analysis, or both), which substances are covered, what is the mode of analysis, what is the extent of temporal and spatial differentiation regarding the emission inventory, what type of fate and exposure models are used, what is the extent of temporal and spatial differentiation in fate and exposure models, which kinds of mathematical relationships are used in effect assessment (e.g., linear or nonlinear dose-response relationships) and which is the point of departure for effect assessment (e.g., NOAEL, LOAEL, BMDL10, ED10, ED50), which exposure pathways and receptors are considered, and what is the extent of spatial differentiation in effect assessment?

\section{DISCUSSION}

As revealed by the literature review, blending elements of RA and LCA offers multifaceted opportunities to adapt a given environmental assessment case study to a specific decision making context. This flexibility, however, requires awareness regarding the use of terminology as well as a number of implications, potential pitfalls, and open issues.

More Stringent and Consistent Use of Terminology. We acknowledge that opinions may diverge on what should be described as combination, integration, hybridization, or complementary use of RA and LCA. Yet, we believe that the ambiguity related to the terms integration, hybridization, and complementary use of RA and LCA in fact is caused by ambiguity related to the meaning or the use of the terms RA and LCA. For example, Kikuchi and Hirao ${ }^{49}$ used a onecompartment box model to estimate the effect of exposure to dichloromethane in an indoor environment (metal degreasing plant) in terms of an overall effect on human health (expressed 


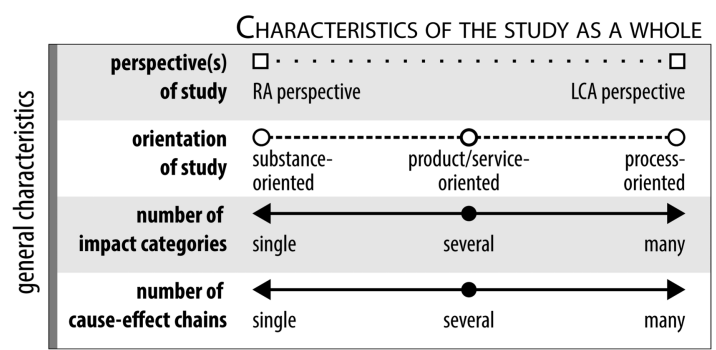

ChaRACTERISTICS PER CAUSE-EFFECT CHAIN

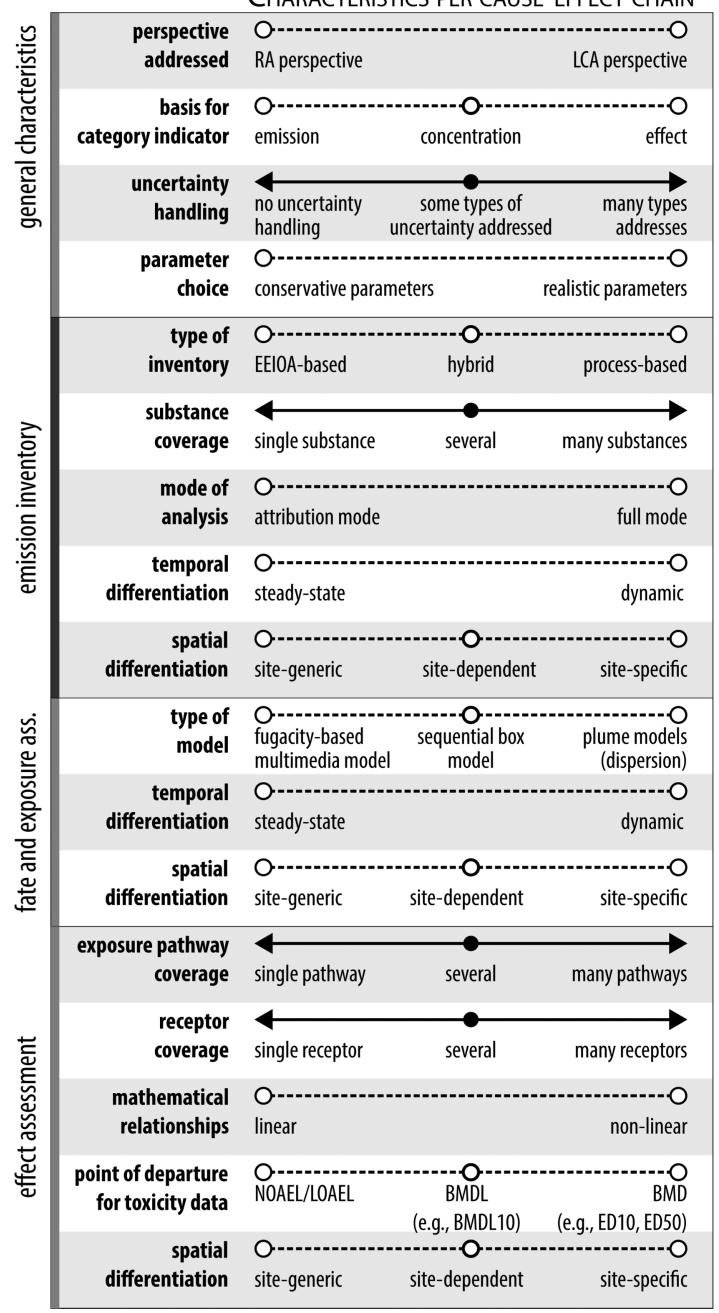

Figure 2. Design space for the modeling of cause-effect chains in environmental assessment case studies. Solid lines with arrows at the ends represent a continuous scale, dashed lines with dots at the end represent a discrete scale, dotted lines with boxes at the end mean that one or several boxes can apply.

as DALY). Walser and colleagues ${ }^{50}$ used a one-compartment box model to estimate the effect of exposure to toluene in indoor environments (printing facility, newsstands, and households) in terms of an overall effect on human health (expressed as comparative toxic units (CTU)). Even though the structure of these two cause-effect chain models is remarkably similar, the use of a one-compartment box model for the estimation of the health effects associated with the exposure to chemicals in an indoor environment was seen as part of a plant-based RA in one study (Kikuchi and Hirao ${ }^{49}$ ) and as part of LCA in the other study (Walser and colleagues ${ }^{50}$ ). This example is illustrative of what seems to be a common source of ambiguity.
The term RA (with regard to chemicals or pathogens) in principle refers to an assessment of the hazard and exposure of a receptor to the stressor at hand, where the goal of the assessment generally is to achieve a basis to decide whether the risk is acceptable or not, that is, whether risk management actions are needed. The term LCA, on the other hand, in principle refers to an assessment of impacts caused by emissions throughout the life cycle of a product or service, where the goal of the assessment is to compare environmental impacts between different alternative products or services fulfilling similar functions, or to compare different stages of the life cycle.

In our opinion, the perspectives addressed in a given case study should determine whether the study is referred to as RA or LCA, or a combination of RA and LCA. A case study that only addresses the RA perspective could be said to adhere to a traditional RA framework. A case study that only addresses the LCA perspective could be said to adhere to a traditional LCA framework. A case study addressing both perspectives adheres neither to a traditional RA nor a traditional LCA framework. A combination or integration of RA and LCA thus is only achieved when both the RA perspective and the LCA perspective are accounted for in a given case study. This is the case only for the case studies belonging to clusters $3 \mathrm{~B}$ and 3 .

Case studies making a distinction between impact categories at different spatial scales, but essentially sticking to an LCA framework (i.e., only addressing the LCA perspective), in our opinion do not imply a combination or integration of RA and LCA, even though the local analysis may be inspired by causeeffect chain models previously used in (chemical or microbial) RA due to its local focus (cluster 3A). To speak of a combination, integration, or hybridization of RA and LCA when different ingredients (i.e., the environmental processes and phenomena that are to be incorporated, the mathematical relationships postulated for each of these phenomena, and the chemical and environmental data needed in these relationships) are exchanged between RA and LCA, we think, may be misleading and confusing. In particular, LCIA rather than RA may be the preferred term if a given cause-effect chain model is used to address the LCA perspective, even if it has been adapted from cause-effect chain models that have been commonly used in an RA framework.

These findings and recommendations, we believe, are in line with, and corroborate the analysis by Udo de Haes and colleagues. $^{17}$

Implications. The case studies provided evidence that cause-effect chain models with different structures (i.e., different degrees of spatial and temporal differentiation, consideration or ignorance of subpopulation effects, and linear or nonlinear mathematical relationships in effect assessment) can coexist in one and the same environmental assessment case study. Here we discuss in particular the implications for scaling to a functional unit, highlighted by Udo de Haes and colleagues $^{17}$ as main difference between RA and LCA at the level of the overall model structure, and the estimation of effects at different spatial scales.

Scaling to a Functional Unit. The implications for scaling to a functional unit is closely related to the two modes of analysis identified by Udo de Haes and colleagues, ${ }^{70}$ namely the attribution mode of analysis and the full mode of analysis.

In the attribution mode of analysis, a specified social demand or a specific function is the starting point, and all emissions 
related to this demand or function are included in the analysis. $^{70}$ The attribution mode of analysis is typical of traditional LCA, where the LCI includes resource use and emissions with reference to a functional unit (e.g., adequate treatment of the wastewater for 100000 person equivalents during a year), and normally covers only a fraction of the emissions of the contributing processes (e.g., the fraction of the particulate matter emissions of a power plant corresponding to the electricity delivered to the wastewater treatment plant). This implies that the emissions related to the functional unit account for only part of the total exposure of various receptors (e.g., inhalation of particulate matter in the vicinity of the power plant). As a result, effect assessment in LCIA traditionally builds upon linear dose-response relationships. Linear dose-response relationships assume the same slope anywhere in the dose or concentration range and essentially disregard any effect-thresholds or other dose-dependent relationships.

In the full mode of analysis, emissions are included to their full extent rather than with reference to a functional unit. ${ }^{70}$ The full mode of analysis is typical of traditional RA. For example, in an RA study addressing the human health and ecological risks related to land application of sewage sludge, the total load of contaminants (from this source) is considered rather than the fraction of the emissions that are related to a specific product or service contributing contaminants to the urban drainage system, as might be the case in an LCA study. In such an RA study, site-specific fate, transport, and exposure models are usually used to compare the predicted exposure and a threshold value. For such a threshold comparison, it makes little sense to base the predicted exposure on emissions scaled to a functional unit.

However, site-specific fate and exposure models have also been used in an LCA framework, for example, in the context of sewage sludge management ${ }^{45,54}$ or contaminated site remediation. ${ }^{43,44}$ In general, it can be said that the integration of sitespecific fate and exposure models usually applies to a specific central process or site (e.g., water treatment plant, contaminated site). For this central process, the underlying emission inventories may correspond with the full mode of analysis, and the effect assessment may contain nonlinear mathematical relationships. Yet, scaling to a functional unit is still possible, but must simply take place after effect assessment. If, for example, pathogen risk is estimated for a given sewage sludge management option, the estimated burden of disease rather than the emissions should be scaled to the functional unit. ${ }^{71}$

Potential Impacts or Actual Impacts. The absence of spatial and temporal detail in traditional LCI (in combination with scaling to a functional unit and the use of linear dose-response relationships) puts constraints on the capacity of LCA to predict actual impacts. ${ }^{72}$ As a result, impacts estimated in LCA are usually referred to as potential impacts. This expression indicates that it is unclear where and to what extent the impact will actually become manifest, given that the cause-effect chains are not modeled in a site-specific manner. However, through efforts toward spatial and temporal differentiation in LCI and LCIA, as well as the integration of site-specific fate and exposure models into LCIA, certain indicators estimated in LCA may become more akin to what could be described as predictions of actual impacts.

Kikuchi and Hirao, ${ }^{49}$ for instance, compared and contrasted local and global human health impacts associated with different metal degreasing processes. To this end, their study combined conventional LCIA models for emissions at the global scale with site-specific fate and exposure models established within RA for emissions at the local scale. At the global scale, global warming potential and human toxicity were considered midpoints affecting the end point human health. At the local scale, exposure of workers and residents to process chemicals were considered. The human health impacts estimated with site-specific models, and those estimated with conventional (site-generic) LCIA models were both expressed in terms of a common category indicator (DALY). But Kikuchi and Hirao ${ }^{49}$ have given consideration to the difference between potential impacts and predicted actual impacts by explicitly distinguishing actual DALYs (obtained from a site-specific assessment of local impacts related to local emissions) and marginal DALYs (obtained from a site-generic assessment of global impacts elsewhere).

Potential Pitfalls. When designing an environmental assessment case study that features elements of RA and LCA, modeling choices reflecting certain preferences are inevitable, as with any type of environmental assessment. ${ }^{1,73-75}$ Here, we shed light on one particular bias that may result from model asymmetry. Furthermore, we discuss the risks of double counting, concealing relevant details, and inconsistent choice of parameter values. These potential pitfalls will be explained and illustrated for a hypothetical environmental assessment of two different sewage sludge management options: land application of sewage sludge and incineration of sewage sludge with subsequent phosphorus recovery.

Typology of Cause-Effect Chain Models. The emission of chemical pollutants or pathogens to the soil upon land application of sewage sludge may affect soil quality and contaminate water and food supplies. In a similar way, emissions to air upon incineration of sewage sludge may affect air quality. In an LCA of sewage sludge management options, these emissions would belong to the foreground system. Emissions from a power station delivering energy for the sewage sludge treatment operations under consideration, in contrast, would belong to the background system. In any case, the effects resulting from emissions in the foreground or background system may affect people living in the vicinity of the processes under consideration, or elsewhere. For example, contaminated food may be consumed in the vicinity of the land application site, or transported further away for consumption.

In a given environmental assessment case study blending elements of RA and LCA, certain cause-effect chains can in principle be described by site-specific fate and exposure models. This means that the emissions, receptors and effects are localized in the assessment. For example, the exposure of the population living in the vicinity of the sludge incineration plant, or the exposure of the population consuming food grown on sludge amended fields, to emissions of chemical pollutants may be assessed in a site-specific manner. In a similar way, the exposure of the population living around a given power station, delivering energy to the sewage sludge treatment operations under consideration, to particular matter emissions may be assessed in a site-specific manner. Other cause-effect chains are not usually described by site-specific fate and exposure models. This means that emissions, receptors, and effects are not localized. The effects of carbon dioxide emissions from the power station delivering energy to the sewage sludge treatment operations, for example, are not usually related to a specific population. 
Potential Bias Due to Model Asymmetry. If a given study combines the different perspectives offered by RA and LCA (clusters $3 \mathrm{~B}$ and $3 \mathrm{C}$ ), the RA perspective is likely to consist of a comparison of "localized" exposures with thresholds. Yet, this threshold comparison is usually only done for processes in the foreground system. Processes in the background system may be ignored in the threshold comparison. Within the RA perspective, there hence seems to be an asymmetry between "localized" risks located at different places. "Localized-here" risks in the immediate sphere of interest to the stakeholders and decision makers "here" (e.g., the municipality, the wastewater treatment plant operator, and people living in the vicinity of the treatment operations under consideration) are assessed, whereas "localized-there" risks elsewhere are not assessed and often cannot be so due to the nature of the analysis. One could argue that this asymmetry is not so problematic because stakeholders and decision makers elsewhere hopefully make sure that acceptable levels of "localized" risks are not exceeded in their immediate sphere of interest and influence. However, there may still be an asymmetry in power, that is, some stakeholders and decision makers may be more powerful than others in setting and enforcing thresholds.

A perhaps more covert form of model asymmetry may emerge upon integration of site-specific models in the LCA perspective with intent to more meaningfully evaluate impacts of interest to stakeholders and decision makers "here" (clusters $3 \mathrm{~A}$ and $3 \mathrm{C}$ ). The integration of site-specific models for certain impact categories often means that "localized-here" impacts are modeled at the local scale using site-specific models, whereas "localized-there" impacts are modeled using site-generic models. In other words, "localized-there" impacts are treated in a similar way as "unlocalized" impacts. In the particular example of the popular USEtox model, this means assuming that "localized-there" air emissions are initially diluted in an air compartment that could be much larger than the dilution effect modeled for "localized-here" air emissions. This asymmetry of modeling "localized-here" impacts differently from "localizedthere" impacts could be said to correspond to an implicit value judgment. To which extent such a model asymmetry affects the overall results is unclear and represents an interesting opportunity for further investigation.

Finally, bias due to model asymmetry could also be introduced if emissions of different kinds of contaminants with similar spatial range of influence and similar cause-effect chains (e.g., human toxicity and pathogen impact) are modeled based on different degrees of site-specificity. For example, Heimersson and colleagues ${ }^{45}$ compared pathogen impact (referred to as pathogen risk in the respective study) estimated based on site-specific models and human toxicity estimated based on models with a lesser degree of spatial and temporal differentiation. It is unclear to which extent the relative importance of pathogen impact and human toxicity is biased by the differences in model structure.

Double Counting. The risk of double counting mainly applies if site-specific characterization models are applied to "localized-here" emissions of a certain type separately, whereas other characterization models are based on emissions inventories representing both "localized-there" and "unlocalized" emissions together. Say a given study evaluates, among other impact categories, human toxicity resulting from heavy metal emissions at a sewage sludge land application site ("localized-here") using site-specific models, whereas the human toxicity resulting from emissions of heavy metals and other chemicals elsewhere ("localized-there" and "unlocalized") are dealt with using an LCIA model based on a larger spatial scale. One must now be careful that the "localized-here" heavy metal emissions are not accidentally aggregated with the "localized-there" and "unlocalized" heavy metal emissions elsewhere because heavy metal emissions would then be accounted for twice, once as total input to the calculations of "localized-here" impacts and once as partial input to the calculations of impacts from "localized-there" and "unlocalized" emissions.

Possible solutions for the problem of double counting have been discussed previously. ${ }^{62,76}$ Mouron and colleagues ${ }^{62}$ suggested that double counting could be avoided by arranging sustainability attributes obtained through RA or LCA in a strictly hierarchical order such that each attribute only occurs once in a hierarchical attribute tree. Alvarez-Gaitan and colleagues $^{76}$ suggested to scale EEIOA results with system completeness factors that eliminate the "localized-here" emissions from the EEIOA inventory prior to aggregation with process LCI results representing "localized-here" emissions.

Inadvertent Inconsistencies in Fate and Exposure Modeling. The rationale followed by RA usually is to identify the exposure pathways and parameter choices with the highest effect per individual exposed. Such an approach is perfectly acceptable and appropriate when addressing the RA perspective. Yet, it may not be appropriate when addressing the LCA perspective, as a potentially larger number of people may be exposed through a less critical exposure pathway, leading to a potentially higher overall effect. There is a risk of inadvertently transferring assumptions and parameter value choices from an RA framework to an LCA framework in at least two ways.

To include pathogen impacts (expressed as burden of disease and referred to as pathogen risk in the respective study) in LCA of wastewater management, Harder and colleagues ${ }^{54}$ used sitespecific models established within QMRA. Essentially, the exposure pathways and parameter choices were derived based on an RA framework. The exposure pathways with correspondent parameter values may reflect nominal system performance (reflecting routine operation under steady-state conditions) or bypass situations (reflecting periods of nonroutine operation). The parameter values chosen in either case may be conservative. If a given cause-effect chain is modeled to reflect periods of nonroutine operation and/or realistic worstcase assumptions, the direct integration of the results into an LCA framework in which average performance is generally assumed can thus be problematic, as the model may not be parametrized in accordance with the principles applied in the LCA framework.

Furthermore, upon aggregation and scaling to a functional unit, details regarding individual exposure pathways and subpopulation effects may get lost, as exemplified by the study by Heimersson and colleagues. ${ }^{45}$ This practice is acceptable if the study intends to identify the wastewater management option with the best environmental performance (LCA perspective), as was the case in the study by Heimersson and colleagues. ${ }^{45}$ However, if pathogen risk is small compared to other LCA derived burdens of disease (where the burden of disease may be distributed to a larger number of individuals), aggregation and scaling to a functional unit may conceal the fact that pathogen risk may still be higher than acceptable for certain individuals in the population from an RA perspective. ${ }^{71}$ The same holds for chemical risks and highlights the 
complementarity of the perspectives offered by RA and LCA, respectively.

Inadvertent Inconsistencies in the Use of Toxicity Data. In an RA framework, effect assessment for threshold effects can be based on the no observed adverse effect level (NOAEL) or the lowest observed adverse effect level (LOAEL). A different approach is the benchmark-dose (BMD) approach, which is applicable for both threshold and nonthreshold effects, and where the point of departure for risk characterization typically is the BMDL10 (the lower limit of a one-sided 95\% confidence interval on the BMD10). Whichever value is chosen as point of departure, a set of assessment factors (AFs) or uncertainty factors (UFs) are applied in order to obtain a reference dose (RfD) that can subsequently be compared with the predicted human intake of a given substance. In an LCA framework, the point of departure for effect assessment usually is ED10 (BMD10) or ED50 data. Also here, a set of AFs or UFs are applied in order to derive slope factors for use in LCIA. When site-specific fate and transport models are taken from an RA framework to an LCA framework, one should be careful not to directly transfer toxicity data from the RA framework to the LCA framework, as the set of AFs or UFs is different in the two frameworks.

Open Issues and Further Opportunities. Recent environmental assessment case studies blending elements of RA and LCA have demonstrated considerable cross-fertilization between RA and LCA, and a further exchange of ideas and methods between the RA and LCA communities may be worthwhile. Particularly, the issue of how to handle variability and uncertainty, and the possibility to integrate nonstandard operation scenarios in LCA deserve some further attention.

Variability and Uncertainty. In RA of chemicals, it is common to distinguish between variability (i.e., quantifiable uncertainty that cannot be reduced by further research and measurements) and uncertainty (i.e., quantifiable uncertainty that can be reduced by further research and measurements). ${ }^{3}$ There are generally two ways of dealing with uncertainty. ${ }^{3}$ Under a deterministic risk assessment framework, a sense of uncertainty is tackled by introducing worst-case assumptions and safety factors. ${ }^{77}$ A qualitatively different way of dealing with uncertainty in RA of chemicals is to adopt a probabilistic risk assessment framework and to integrate uncertainty in risk characterization by calculating a probability density instead of a conservative point estimate.

Also in LCA, the necessity to deal with uncertainty has long been recognized. ${ }^{1,74,78-83}$ To address the role of value choices, Hofstetter and colleagues, ${ }^{78}$ for instance, suggested to conduct several structurally identical types of LCA, each based on a coherent but different set of values. Other efforts include the quantification of parameter uncertainty. ${ }^{84}$ Hofstetter and colleagues $^{78}$ even attempted to include a proxy indicator for unknown damage into LCA, which in principle is an attempt to estimate the uncertainty associated with something that is not quantifiable at the time of the analysis, but would in principle be quantifiable provided enough information were available.

The present study did not probe how the different case studies dealt with variability and uncertainty, as this would go beyond the scope of the present study. For case studies addressing both the RA and LCA perspective (clusters $3 \mathrm{~B}$ and $3 C$ ), it would be interesting to investigate further whether it is problematic to deal with variability and uncertainty in different ways in the RA perspective and the LCA perspective, respectively.
Integration of Nonstandard Operation Scenarios into LCA. The integration of nonstandard operation scenarios (e.g., nonroutine operation, accidents, technological disasters) into LCA would be a further opportunity for cross-fertilization between RA and LCA. ${ }^{38,85-88}$ Currently, hazardous events and their possible consequences are often taken into consideration in RA when new operations are established, whereas in LCA, normally only routine operations under steady-state conditions are considered.

Integration of Disparate Subpopulation Effects into LCA. Furthermore, just as in RA, disparate subpopulation effects could in principle be addressed in LCA through, for instance, separate consideration of children, workers, or elderly people.

\section{CONCLUDING REMARKS}

As revealed by the present study, environmental assessment case studies building on elements taken from RA and LCA can be designed in many different ways. The in-depth analysis of the case studies gave evidence for increasingly blurred boundaries between RA and LCA as well as some confusion regarding the use of terminology. We believe that RA and LCA provide complementary perspectives relevant in many different environmental assessments. In our opinion, it is adequate to speak of combination, integration, or combined use of RA and LCA only if a given case study encompasses both perspectives (clusters $3 \mathrm{~B}$ and $3 \mathrm{C}$ ). Speaking of combination, integration, combined use, or even hybridization of RA and LCA, when in fact only technical elements (i.e., the environmental processes and phenomena that are to be incorporated, the mathematical relationships postulated for each of these phenomena, and the chemical and environmental data needed in these relationships) are exchanged between RA and LCA, may be misleading and confusing. An exchange of technical elements may nevertheless be valuable and useful. But there are a number of implications and pitfalls at the level of the model structure, which analysts should be aware of when designing and interpreting an environmental assessment blending elements of RA and LCA. Notably, the potential asymmetry between the handling of local risks and impacts in the immediate sphere of interest to the decision maker ("localized-here") and local risks and impacts elsewhere on the globe ("localized-there") may correspond to an implicit value judgment and deserves particular attention, as it may go counter to the initial idea of LCA, namely that impacts at different locations should be treated in a similar way.

We conclude this paper by emphasizing that the design of a case study that builds on elements of RA and LCA requires careful consideration of a number of choices regarding methodology and reporting of results. Making these choices sensibly and transparently will contribute to the usefulness of environmental assessments blending elements of RA and LCA as decision support. The design space proposed in the present study may facilitate conscious and purposeful design and transparent communication of case studies blending elements of both RA and LCA. The use of the design space may help analysts and decision makers avoid pitfalls and explore the full potential of environmental case studies blending elements of RA and LCA.

\section{ASSOCIATED CONTENT}

\section{Supporting Information}

The Supporting Information is available free of charge on the ACS Publications website at DOI: 10.1021/acs.est.5b03302. 
Characteristics of the case studies reviewed in this study are summarized in Tables S1-S6 (PDF)

\section{AUTHOR INFORMATION}

\section{Corresponding Author}

*R. Harder. Phone: +46 (0)31 77229 99. E-mail: robin. harder@wetryharder.ch. Visiting address: Kemigården 4, 412 96 Gothenburg, Sweden.

\section{Notes}

The authors declare no competing financial interest.

\section{ACKNOWLEDGMENTS}

The Swedish Research Council for Environment, Agricultural Sciences and Spatial Planning (FORMAS) funded this research under grant agreements No. 2012-1122 and 2012-2148. The authors thank Magnus Myréen and Magnus Gustafsson (both at Chalmers University of Technology) for valuable suggestions on how to improve selected sections of the original manuscript in terms of language and structure. The authors also thank the four anonymous reviewers and the editor for their valuable contributions that helped to make the paper more focused and coherent.

\section{REFERENCES}

(1) Cowell, S.; Fairman, R.; Lofstedt, R. Use of risk assessment and life cycle assessment in decision making: A common policy research agenda. Risk Anal. 2002, 22 (5), 879-894.

(2) Ecological Risk Assessment, 2nd ed.; Suter, G., II, Ed.; CRC Press: Boca Raton, FL, 2006.

(3) Risk Assessment of Chemicals - An Introduction, 2nd ed.; Van Leeuwen, C., Vermeire, T., Eds.; Springer: Dordrecht, The Netherlands, 2007.

(4) Baumann, H.; Tillman, A.-M. The Hitch Hiker's Guide to LCA; Studentlitteratur: Lund, Sweden, 2004.

(5) Hauschild, M.; Goedkoop, M.; Guinée, J.; Heijungs, R.; Huijbregts, M.; Jolliet, O.; Margni, M.; De Schryver, A.; Humbert, S.; Laurent, A.; Sala, S.; Pant, R. Identifying best existing practice for characterization modeling in life cycle impact assessment. Int. J. Life Cycle Assess. 2013, 18 (3), 683-697.

(6) Guinée, J.; Heijungs, R. A proposal for the classification of toxic substances within the framework of life cycle assessment of products. Chemosphere 1993, 26 (10), 1925-1944.

(7) Guinée, J.; Heijungs, R.; Van Oers, L.; Sleeswijk, A.; van de Meent, D.; Vermeire, T.; Rikken, M. USES uniform system for the evaluation of substances inclusion of fate in LCA characterisation of toxic releases applying USES 1.0. Int. J. Life Cycle Assess. 1996, 1 (3), $133-138$.

(8) Heijungs, R.; Guinee, J.; Huppes, G.; Lankreijer, R.; Udo De Haes, H.; Wegener Sleeswijk, A.; Ansems, A.; Eggels, P.; van Duin, R.; de Goede, $\mathrm{H}$. Environmental life cycle assessment of products; Centre of Environmental Science: Leiden, The Netherlands, 1992.

(9) Hertwich, E.; Sheng, P.; Koshland, C. Flexible method for including environmental toxicity in DfE and LCA. IEEE International Symposium on Electronics and the Environment 1996, 269-274.

(10) Keller, D.; Wahnschaffe, U.; Rosner, G.; Mangelsdorf, I. Considering human toxicity as an impact category in life cycle assessment. Int. J. Life Cycle Assess. 1998, 3 (2), 80-85.

(11) Aramaki, T.; Galal, M.; Hanaki, K. Estimation of reduced and increasing health risks by installation of urban wastewater systems. Water Sci. Technol. 2006, 53 (9), 247-252.

(12) Hofstetter, P.; Bare, J.; Hammitt, J.; Murphy, P.; Rice, G. Tools for comparative analysis of alternatives: Competing or complementary perspectives? Risk Anal. 2002, 22 (5), 833-851.

(13) Matthews, H.; Lave, L.; MacLean, H. Life cycle impact assessment: A challenge for risk analysts. Risk Anal. 2002, 22 (5), $853-860$.
(14) Tukker, A. Risk analysis, life cycle assessment - The common challenge of dealing with the precautionary frame (based on the toxicity controversy in Sweden and the Netherlands). Risk Anal. 2002, 22 (5), 821-832.

(15) Bare, J. Risk assessment and life-cycle impact assessment (LCIA) for human health cancerous and noncancerous emissions: Integrated and complementary with consistency within the USEPA. Hum. Ecol. Risk Assess. 2006, 12 (3), 493-509.

(16) Russell, A. Hum. Ecol. Risk Assess. and life cycle assessment: Intersections, collisions, and future directions. Hum. Ecol. Risk Assess. 2006, 12 (3), 427-430.

(17) Udo De Haes, H.; Sleeswijk, A.; Heijungs, R. Similarities, differences and synergisms between HERA and LCA - An analysis at three levels. Hum. Ecol. Risk Assess. 2006, 12 (3), 431-449.

(18) Socolof, M.; Geibig, J. Evaluating human and ecological impacts of a product life cycle: The complementary roles of life-cycle assessment and risk assessment. Hum. Ecol. Risk Assess. 2006, 12 (3), 510-527.

(19) Olsen, S.; Christensen, F.; Hauschild, M.; Pedersen, F.; Larsen, H.; Tørsløv, J. Life cycle impact assessment and risk assessment of chemicals - A methodological comparison. Environ. Impact Assess. Rev. 2001, 21 (4), 385-404.

(20) Owens, J. Life-cycle assessment in relation to risk assessment: An evolving perspective. Risk Anal. 1997, 17 (3), 359-365.

(21) Wegener Sleeswijk, A.; Heijungs, R.; Erler, S. Risk assessment and life-cycle assessment: Fundamentally different yet reconcilable. Greener Manage. Int. 2003, 2003 (41), 77-87.

(22) Volkwein, S.; Hurtig, H.-W.; Klöpffer, W. Life Cycle Assessment of contaminated sites remediation. Int. J. Life Cycle Assess. 1999, 4 (5), 263-274.

(23) Scheringer, M.; Halder, D.; Hungerbühler, K. Comparing the environmental performance of fluorescent whitening agents with peroxide bleaching of mechanical pulp. J. Ind. Ecol. 1999, 3 (4), 77-95.

(24) Saouter, E.; Van Hoof, G.; Pittinger, C.; Feijtel, T. The effect of compact formulations on the environmental profile of Northern European granular laundry detergents - Part I: Environmental risk assessment. Int. J. Life Cycle Assess. 2001, 6 (6), 363-372.

(25) Saouter, E.; Van Hoof, G.; Feijtel, T.; Owens, J. The effect of compact formulations on the environmental profile of Northern European granular laundry detergents - Part II: Life cycle assessment. Int. J. Life Cycle Assess. 2002, 7 (1), 27-38.

(26) Nishioka, Y.; Levy, J.; Norris, G.; Wilson, A.; Hofstetter, P.; Spengler, J. Integrating risk assessment and life cycle assessment: A case study of insulation. Risk Anal. 2002, 22 (5), 1003-1017.

(27) Nishioka, Y.; Levy, J.; Norris, G.; Bennett, D.; Spengler, J. A risk-based approach to health impact assessment for input-output analysis - Part 1: Methodology. Int. J. Life Cycle Assess. 2005, 10 (3), 193-199.

(28) Nishioka, Y.; Levy, J.; Norris, G.; Bennett, D.; Spengler, J. A risk-based approach to health impact assessment for input-output analysis - Part 2: Case study of insulation. Int. J. Life Cycle Assess. 2005, 10 (4), 255-262.

(29) Nishioka, Y.; Levy, J.; Norris, G. Integrating air pollution, climate change, and economics in a risk-based life-cycle analysis: A case study of residential insulation. Hum. Ecol. Risk Assess. 2006, 12 (3), 552-571.

(30) Rehr, A.; Small, M.; Scott Matthews, H.; Hendrickson, C. Economic sources and spatial distribution of airborne chromium risks in the U.S. Environ. Sci. Technol. 2010, 44 (6), 2131-2137.

(31) Wright, H.; Zhang, Q.; Mihelcic, J. Integrating economic inputoutput life cycle assessment with risk assessment for a screening-level analysis. Int. J. Life Cycle Assess. 2008, 13 (5), 412-420.

(32) Wegener Sleeswijk, A.; Heijungs, R. GLOBOX: A spatially differentiated global fate, intake and effect model for toxicity assessment in LCA. Sci. Total Environ. 2010, 408 (14), 2817-2832.

(33) Kounina, A.; Margni, M.; Shaked, S.; Bulle, C.; Jolliet, O. Spatial analysis of toxic emissions in LCA: A sub-continental nested USEtox model with freshwater archetypes. Environ. Int. 2014, 69, 67-89. 
(34) Dhingra, R.; Naidu, S.; Upreti, G.; Sawhney, R. Sustainable nanotechnology: Through green methods and life-cycle thinking. Sustainability 2010, 2 (10), 3323-3338.

(35) Kuczenski, B.; Geyer, R.; Boughton, B. Tracking toxicants: Toward a life cycle aware risk assessment. Environ. Sci. Technol. 2011, 45 (1), 45-50.

(36) Shih, H.-C.; Ma, H.-W. Life cycle risk assessment of bottom ash reuse. J. Hazard. Mater. 2011, 190 (1-3), 308-316.

(37) Milazzo, M. F.; Spina, F. The use of the risk assessment in the life cycle assessment framework: Human health impacts of a soybiodiesel production. Manage. Environ. Qual. 2015, 26 (3), 389-406.

(38) Aissani, L.; Jabouille, F.; Bourgois, J.; Rousseaux, P. A new methodology for risk evaluation taking into account the whole life cycle (LCRA): Validation with case study. Process Saf. Environ. Prot. 2012, 90 (4), 295-303.

(39) Cappuyns, V.; Kessen, B. Combining life cycle analysis, human health and financial risk assessment for the evaluation of contaminated site remediation. J. Environ. Plann. Manage. 2014, 57 (7), 1101-1121.

(40) Godin, J.; Ménard, J.-F.; Hains, S.; Deschênes, L.; Samson, R. Combined use of life cycle assessment and groundwater transport modeling to support contaminated site management. Hum. Ecol. Risk Assess. 2004, 10 (6), 1099-1116.

(41) Inoue, Y.; Katayama, A. Two-scale evaluation of remediation technologies for a contaminated site by applying economic inputoutput life cycle assessment: Risk-cost, risk-energy consumption and risk-CO2 emission. J. Hazard. Mater. 2011, 192 (3), 1234-1242.

(42) Lemming, G.; Hauschild, M.; Chambon, J.; Binning, P.; Bulle, C.; Margni, M.; Bjerg, P. Environmental impacts of remediation of a trichloroethene-contaminated site: Life cycle assessment of remediation alternatives. Environ. Sci. Technol. 2010, 44 (23), 9163-9169.

(43) Lemming, G.; Chambon, J.; Binning, P.; Bjerg, P. Is there an environmental benefit from remediation of a contaminated site? Combined assessments of the risk reduction and life cycle impact of remediation. J. Environ. Manage. 2012, 112, 392-403.

(44) Sparrevik, M.; Saloranta, T.; Cornelissen, G.; Eek, E.; Fet, A.; Breedveld, G.; Linkov, I. Use of life cycle assessments to evaluate the environmental footprint of contaminated sediment remediation. Environ. Sci. Technol. 2011, 45 (10), 4235-4241.

(45) Heimersson, S.; Harder, R.; Peters, G.; Svanström, M. Including pathogen risk in life cycle assessment of wastewater management. 2 . Quantitative comparison of pathogen risk to other impacts on human health. Environ. Sci. Technol. 2014, 48 (16), 9446-9453.

(46) Kobayashi, Y.; Peters, G. M.; Ashbolt, N. J.; Heimersson, S.; Svanström, M.; Khan, S. J. Global and local health burden trade-off through the hybridisation of quantitative microbial risk assessment and life cycle assessment to aid water management. Water Res. 2015, 79, 26-38.

(47) Ribera, G.; Clarens, F.; Martínez-Lladó, X.; Jubany, I.; Martí, V.; Rovira, M. Life cycle and human health risk assessments as tools for decision making in the design and implementation of nanofiltration in drinking water treatment plants. Sci. Total Environ. 2014, 466-467, $377-386$.

(48) Wenzel, H.; Larsen, H.; Clauson-Kaas, L.; Høibye, L.; Jacobsen, $\mathrm{N}$. Weighing environmental advantages and disadvantages of advanced wastewater treatment of micro- pollutants using environmental life cycle assessment. Water Sci. Technol. 2008, 57 (1), 27-32.

(49) Kikuchi, Y.; Hirao, M. Practical method of assessing local and global impacts for risk- based decision making: A case study of metal degreasing processes. Environ. Sci. Technol. 2008, 42 (12), 4527-4533.

(50) Walser, T.; Juraske, R.; Demou, E.; Hellweg, S. Indoor exposure to toluene from printed matter matters: Complementary views from life cycle assessment and risk assessment. Environ. Sci. Technol. 2014, 48 (1), 689-697.

(51) Beck, A.; Scheringer, M.; Hungerbuhler, K. Fate modelling within LCA: The case of textile chemicals. Int. J. Life Cycle Assess. 2000, 5 (6), 335-344.

(52) Schwab, O.; Bayer, P.; Juraske, R.; Verones, F.; Hellweg, S. Beyond the material grave: Life cycle impact assessment of leaching from secondary materials in road and earth constructions. Waste Manage. 2014, 34 (10), 1884-1896.

(53) Sablayrolles, C.; Gabrielle, B.; Montrejaud-Vignoles, M. Life cycle assessment of biosolids land application and evaluation of the factors impacting human toxicity through plant uptake. J. Ind. Ecol. 2010, 14 (2), 231-241.

(54) Harder, R.; Heimersson, S.; Svanström, M.; Peters, G. Including pathogen risk in life cycle assessment of wastewater management. 1. Estimating the burden of disease associated with pathogens. Environ. Sci. Technol. 2014, 48 (16), 9438-9445.

(55) Kikuchi, Y.; Hirao, M. Local risks and global impacts considering plant-specific functions and constraints: A case study of metal parts cleaning. Int. J. Life Cycle Assess. 2010, 15 (1), 17-31.

(56) Kikuchi, E.; Kikuchi, Y.; Hirao, M. Analysis of risk trade-off relationships between organic solvents and aqueous agents: Case study of metal cleaning processes. J. Cleaner Prod. 2011, 19 (5), 414-423.

(57) Herva, M.; Franco-Uría, A.; Carrasco, E.; Roca, E. Application of fuzzy logic for the integration of environmental criteria in ecodesign. Expert Syst. Appl. 2012, 39 (4), 4427-4431.

(58) Barberio, G.; Scalbi, S.; Buttol, P.; Masoni, P.; Righi, S. Combining life cycle assess- ment and qualitative risk assessment: The case study of alumina nanofluid production. Sci. Total Environ. 2014, 496, 122-131.

(59) Song, Q.; Zeng, X.; Li, J.; Duan, H.; Yuan, W. Environmental risk assessment of CRT and PCB workshops in a mobile e-waste recycling plant. Environ. Sci. Pollut. Res. 2015, 22 (16), 12366-12373.

(60) Benetto, E.; Tiruta-Barna, L.; Perrodin, Y. Combining lifecycle and risk assessments of mineral waste reuse scenarios for decision making support. Environ. Impact Assess. Rev. 2007, 27 (3), 266-285.

(61) Carpenter, A.; Gardner, K.; Fopiano, J.; Benson, C.; Edil, T. Life cycle based risk assessment of recycled materials in roadway construction. Waste Manage. 2007, 27 (10), 1458-1464.

(62) Mouron, P.; et al. Sustainability assessment of crop protection systems: SustainOS methodology and its application for apple orchards. Agr. Syst. 2012, 113, 1-15.

(63) Potting, J.; Hauschild, M. Z. Spatial differentiation in life cycle impact assessment: A decade of method development to increase the environmental realism of LCIA. Int. J. Life Cycle Assess. 2006, 11 (1), $11-13$.

(64) Murray, C. Quantifying the burden of disease: The technical basis for disability-adjusted life years. Bull. World Health Organ. 1994, 72, 429-445.

(65) Liu, K.-R.; Ko, C.-Y.; Fan, C.; Chen, C.-W. Combining risk assessment, life cycle assessment, and multi-criteria decision analysis to estimate environmental aspects in environmental management system. Int. J. Life Cycle Assess. 2012, 17 (7), 845-862.

(66) Suh, S.; Huppes, G. Methods for life cycle inventory of a product. J. Cleaner Prod. 2005, 13 (7), 687-697.

(67) Baumann, H.; Cowell, S. An evaluative framework for conceptual and analytical ap- proaches used in environmental management. Greener Manage. Int. 1999, 26, 109-122.

(68) Zijp, M. C.; Heijungs, R.; van der Voet, E.; van de Meent, D.; Huijbregts, M. A. J.; Hollander, A.; Posthuma, L. An Identification Key for Selecting Methods for Sustainability Assessments. Sustainability 2015, 7, 2490-2512.

(69) U.S. National Research Council (NRC). Science and decisions, advancing risk assessment; U.S. National Academies Press: Washington, DC, 2009

(70) Udo de Haes, H.; Heijungs, R.; Huppes, G.; van der Voet, E.; Hettelingh, J.-P. Full mode and attribution mode in environmental analysis. J. Ind. Ecol. 2000, 4 (1), 45-56.

(71) Harder, R.; Schoen, M.; Peters, G. Including pathogen risk in life cycle assessment of wastewater management. Implications for the choice of functional unit. Environ. Sci. Technol. 2015, 49 (1), 14-15.

(72) Potting, J.; Hauschild, M.; Wenzel, H. 'Less is better' and 'only above threshold': Two incompatible paradigms for human toxicity in life cycle assessment? Int. J. Life Cycle Assess. 1999, 4 (1), 16-24. 
(73) De Schryver, A.; Humbert, S.; Huijbregts, M. The influence of value judgments in life cycle impact assessment of stressors causing human health damage. Int. J. Life Cycle Assess. 2013, 18 (3), 698-706.

(74) Hertwich, E. G.; Hammitt, J. K.; Pease, W. S. A theoretical foundation for life-cycle assessment. Recognizing the role of values in environmental decision making. J. Ind. Ecol. 2000, 4 (1), 13-28.

(75) Rowley, H.; Peters, G.; Lundie, S.; Moore, S. Aggregating sustainability indicators: Beyond the weighted sum. J. Environ. Manage. 2012, 111, 24-33.

(76) Alvarez-Gaitan, J. P.; Peters, G. M.; Rowley, H. V.; Moore, S.; Short, M. D. A hybrid life cycle assessment of water treatment chemicals: An Australian experience. Int. J. Life Cycle Assess. 2013, 18, 1291-1301.

(77) Jager, T.; Vermeire, T.; Rikken, M.; van der Poel, P. Opportunities for a probabilistic risk assessment of chemicals in the European Union. Chemosphere 2001, 43, 257-264.

(78) Hofstetter, P.; Baumgartner, T.; Scholz, R. Modelling the valuesphere and the ecosphere: Integrating the decision makers' perspectives into LCA. Int. J. Life Cycle Assess. 2000, 5 (3), 161-175.

(79) Tukker, A. Philosophy of science, policy sciences and the basis of decision support with LCA: Based on the toxicity controversy in Sweden and the Netherlands. Int. J. Life Cycle Assess. 2000, 5 (3), 177186.

(80) Huijbregts, M. Application of uncertainty and variability in LCA - Part I: A general framework for the analysis of uncertainty and variability in life cycle assessment. Int. J. Life Cycle Assess. 1998, 3 (5), 273-280.

(81) Huijbregts, M. Application of uncertainty and variability in LCA - Part II: Dealing with parameter uncertainty and uncertainty due to choices in life cycle assessment. Int. J. Life Cycle Assess. 1998, 3 (6), 343-351.

(82) Steen, B. On uncertainty and sensitivity of LCA-based priority setting. J. Cleaner Prod. 1997, 5 (4), 255-262.

(83) Ross, S.; Evans, D.; Webber, M. How LCA studies deal with uncertainty. Int. J. Life Cycle Assess. 2002, 7 (1), 47-52.

(84) Ciroth, A.; Srocka, M. How to obtain a precise and representative estimate for parameters in LCA - A case study for the functional unit. Int. J. Life Cycle Assess. 2008, 13 (3), 265-277.

(85) Gale, P. Land application of treated sewage sludge: Quantifying pathogen risks from consumption of crops. J. Appl. Microbiol. 2005, 98, 380-396.

(86) Kane, G.; Stoyell, J.; Howarth, C.; Norman, P.; Vaughan, R. A stepwise life cycle engineering methodology for the clean design of large made to order products. J. Eng. Design 2000, 11 (2), 175-189.

(87) Roes, A.; Patel, M. Life cycle risks for human health: A comparison of petroleum versus bio-based production of five bulk organic chemicals. Risk Anal. 2007, 27 (5), 1311-1321.

(88) Scanlon, K. A.; Lloyd, S. M.; Gray, G. M.; Francis, R. A.; LaPuma, P. An approach to integrating occupational safety and health into life cycle assessment: Development and application of work environment characterization factors. J. Ind. Ecol. 2015, 19 (1), 27-37. 